EESTI NSV TEADUSTE AKADEEMIA TOIMETISED. XII KÖIDE

FOOSIKA-MATEMAATIKA- JA TEHNIKATEADUSTE SEERIA, 1963, NR. 3

ИЗВЕСТИЯ АКАДЕМИИ НАУК ЭСТОНСКОН ССР. ТОМ ХН

СЕРИЯ ФИЗИКО-МАТЕМАТИЧЕСКИХ И ТЕХНИЧЕСКИХ НАУК. 1963, № 3

\title{
ИЗУЧЕНИЕ АКТИВНОСТИ КАТАЛИТИЧЕСКИХ СИСТЕМ НА ОСНОВЕ БИС-ЦИКЛОПЕНТАДИЕНИЛЬНЫХ СОЕДИНЕНИИ ТИТАНА ПРИ ПОЛИМЕРИЗАЦИИ ЭТИЛЕНА
}

\author{
X. KAAP \\ О. КИРРЕТ, \\ член-корреспондент Академии наук Эстонской ССР \\ Г. ШВИНДЛЕРМАН
}

1. О каталитической активности системы $\mathrm{R}_{3} \mathrm{Al}-\left(\mathrm{C}_{5} \mathrm{H}_{5}\right)_{2} \quad \mathrm{TiCl}_{2}$ при полимеризации этилена

Известно, что при взаимодействии $\mathrm{R}_{3} \mathrm{Al}$ с бис-циклопентадиенил-титан-дихлоридом образуется мостиковый комплекс<smiles>[C+](c1ccccc1)c1ccccc1</smiles><smiles></smiles>
$\mathrm{Al}\left\langle_{\mathrm{R}}^{\mathrm{R}}\right.$, который является слабым катализатором полимеризации этилена. Образование высокомолекулярного полиэтилена при применении этого комплекса протекает с достаточной скоростью при 40 aт и $90^{\circ}\left[{ }^{1,8}\right]$. Из работ Бреслоу и др. известно, что при взаимодействии $\mathrm{R}_{2} \mathrm{AlCl}$ и $\left(\mathrm{C}_{5} \mathrm{H}_{5}\right)_{2} \mathrm{TiCl}_{2}$ получается значительно более активная каталитическая система, которая способна вести полимеризацию этилена при атмосферном давлении и комнатной температуре. Однако эта система активна лишь тогда, когда формирование каталитического комплекса происходит в присутствии мономера или когда в реакционной смеси присутствуют небольшие количества кислорода, $\mathrm{HCl}$ или воды $\left[{ }^{2-6}\right]$. При этом, как установлено, каталитическая активность связана с образующимся на одной из про-

межуточных стадий комплексом<smiles>[R]C(Cl)[Al](Cl)(Cl)Cl</smiles>

в состав которого вхо-

дит катион $\left(\mathrm{C}_{5} \mathrm{H}_{5}\right) \mathrm{Ti}^{+} \mathrm{R}\left[{ }^{2}\right]$; цепь превращеннй, происходящих при взаимодействии $\mathrm{R}_{2} \mathrm{AlCl}$ и $\left(\mathrm{C}_{5} \mathrm{H}_{5}\right)_{2} \mathrm{Ti} \mathrm{Cl}_{2}$, наблюдаемых по изменениям окраски, в конечном итоге приводит к неактивному комплексу $\left(\mathrm{C}_{5} \mathrm{H}_{5}\right)_{2} \mathrm{Ti} \mathrm{Cl} \mathrm{Al} \mathrm{RCl}_{2}$ с трехвалентным титаном [7, 8].

В данной работе рассмотрены некоторые причины, обусловливающие более низкую активность катализаторов указанного типа, содержащих $\mathrm{R}_{3} \mathrm{Al}$ по сравнению с катализаторами, содержащими $\mathrm{R}_{2} \mathrm{AlCl}$, а также рассмотрены возможности повышения активности катализаторов, содержащих алюминийтриалкилы, путем превращения $\mathrm{R}_{3} \mathrm{Al}$ в $\mathrm{R}_{2} \mathrm{AlCl}$ in situ.

\section{Экспериментальная часть}

Полимеризацию этилена проводили в проточной системе, в термостатированном стеклянном реакторе, снабженном мешалкой, вводом для газа, бюреткой для подачи компонентов катализатора и холодильником. Загрузка реактора и полимеризация этилена проводились в атмосфере аргона или азота, очищенного от кислорода (до $0,01 \%$ ) и тщательно высушенного (точка росы $-60^{\circ}$ ). Для опытов применяли 99,5\%-ный 
Зависимость выхода полимера на катализаторе $\left(\mathrm{C}_{5} \mathrm{H}_{5}\right)_{2} \mathrm{TiCl}-$ (изо- $\left.\mathrm{C}_{4} \mathrm{H}_{9}\right)_{3} \mathrm{Al}$ от характера растворителя или добавки

\begin{tabular}{|c|c|c|c|c|c|}
\hline \multirow{2}{*}{$\begin{array}{l}\text { Раствори- } \\
\text { тель }\end{array}$} & \multirow[t]{2}{*}{ Добавка } & $\begin{array}{c}\text { Соотноше- } \\
\text { ние, добавка }\end{array}$ & \multirow{2}{*}{$\begin{array}{c}\text { Выход } \\
\text { полимера } \\
2 / \text { / } 2 \text { ль } \\
\left(\mathrm{C}_{5} \mathrm{H}_{5}\right)_{2} \mathrm{TiCl}_{2}\end{array}$} & \multirow{2}{*}{$\begin{array}{l}\text { T-ра плав- } \\
\text { ления } \\
\text { полимера }\end{array}$} & \multirow{2}{*}{$\begin{array}{c}\text { Молеку } \\
\text { лярный } \\
\text { вес }\end{array}$} \\
\hline & & $\left(\text { изо- } \mathrm{C}_{4} \mathrm{H}_{9}\right)_{3} \mathrm{Al}$ & & & \\
\hline Дихлорэтан & \multirow{6}{*}{$\begin{array}{l}\text { каталити- } \\
\text { ческнй } \\
\text { комплекс } \\
\text { не обра- } \\
\text { зуется }\end{array}$} & & 2900 & $128-130^{\circ}$ & 25090 \\
\hline $\begin{array}{l}\text { Тетрахлор- } \\
\text { этан }\end{array}$ & & & 1750 & $126-128^{\circ}$ & 4900 \\
\hline $\begin{array}{l}\text { 1-хлорбутан } \\
\text { Хлороформ }\end{array}$ & & & $\begin{array}{r}200 \\
\text { нет }\end{array}$ & $115-119^{\circ}$ & \\
\hline $\begin{array}{l}\text { 1-хлоргеп- } \\
\text { тан }\end{array}$ & & & нет & & \\
\hline $\begin{array}{l}\text { 1-хлорнонан } \\
\text { Трет. хлор- }\end{array}$ & & & нет & & \\
\hline бутан & & & нет & - & \\
\hline \multirow{2}{*}{$\begin{array}{l}\text { Хлорбензол } \\
\text { Хлористый } \\
\text { винил }\end{array}$} & & & нет & & \\
\hline & & & $\left(-50^{\circ}\right)$ нет & & \\
\hline \multirow{6}{*}{$\begin{array}{c}\text { Толуол } \\
\text {," } \\
\text { ", } \\
\text { " }\end{array}$} & \multirow{6}{*}{$\begin{array}{l}\mathrm{C}_{7} \mathrm{H}_{15} \mathrm{Cl} \\
\mathrm{C}_{9} \mathrm{H}_{19} \mathrm{Cl} \\
\mathrm{HCl} \\
\mathrm{CH}_{2}=\mathrm{CH}- \\
-\mathrm{CH}_{2} \mathrm{Cl} \\
\mathrm{C}_{6} \mathrm{H}_{5} \mathrm{CH}_{2} \mathrm{Cl} \\
\mathrm{TpeT} \mathrm{C}_{4} \mathrm{H}_{9} \mathrm{Cl} \\
\left(\mathrm{C}_{6} \mathrm{H}_{5}\right)_{3} \mathrm{CCl}\end{array}$} & & нет & & \\
\hline & & $1: 1$ & следы & & \\
\hline & & $\begin{array}{l}1: 1 \\
2: 1\end{array}$ & 2400 & $132-134^{\circ}$ & 32100 \\
\hline & & $1: 1$ & 1000 & $130-131^{\circ}$ & 24500 \\
\hline & & $\begin{array}{l}2: 1 \\
1: 1\end{array}$ & $\begin{array}{l}2900 \\
\text { следы }\end{array}$ & $133-135$ & 26000 \\
\hline & & $1: 1$ & 1000 & $131-133^{\circ}$ & 38600 \\
\hline
\end{tabular}

этилен, дополнительно очнщенный от следов ацетилена с помощью реактива Илосвая. Скорость поглощения этилена отсчитывали по разности показаний газовых часов на входе в реактор и на выходе из него: после газовых часов на входе этилен, прежде чем попасть в реактор, высушивался в трубках с $\mathrm{CaCl}_{2}, \mathrm{KOH}$ и раствором тринзобутилалюминия в декане. Растворители и алкилгалогениды, очнщенные и высушенные над $\mathrm{CaCl}_{2}$ и $\mathrm{P}_{2} \mathrm{O}_{5}$, перегоняли в токе азота: все вещества по своим константам соответствовали литературным данным. Бис-циклопентадиенил-титан-дихлорид синтезировали взаимодействием циклопентадиенилнатрия с четыреххлористым титаном в толуольной суспензии [9] т. пл. $287-289^{\circ} \mathrm{C}$ (из толуола). Триизобутилалюминий - техниचеский продукт очищали трехкратным вымораживанием (из раствора в бензине «калоша» и из чистого н-гептана) и перегонкой в вакууме (т. кип. $52-56$ / $2-3$ мм рт. ст.): для работы использовали 1 М раствор в н-гептане. Қачество препарата и концентрацию растворов проверяли аналитически, разлагая 0,3-0,7 мл раствора 20\%-ной $\mathrm{HNO}_{3}$ (при охлаждении сухим льдом) и измеряя объем выделившегося изобутана, с учетом поправки на его растворимость в гептане. Алюминий определяли из той же пробы прибавлением избытка $0,05 \mathrm{M}$ раствора трилона Б и обратным титрованием 0,05M раствором $\mathrm{Pb}\left(\mathrm{NO}_{3}\right)_{2}$ при $\mathrm{pH} 5-6$, в присутствии индикатора - ксиленолового оранжевого [10].

При полимеризации этилена соотношение $\left(\mathrm{C}_{5} \mathrm{H}_{5}\right)_{2} \mathrm{TiCl}_{2}:$ (изо- $\left.\mathrm{C}_{4} \mathrm{H}_{9}\right)_{3} \mathrm{Al}=1: 4$. Концентрация $\left(\mathrm{C}_{5} \mathrm{H}_{5}\right)_{2} \mathrm{TiCl}_{2}-2$ ммоля/л объем растворителя $100 \mathrm{M \Omega}$.

При использовании алкилгалогенидов в качестве активирующих добавок весь процесс проводился в толуоле. 
Температура полимеризации в опытах по изучению влияния алкилгалогенидов постоянная - $+40^{\circ}$.

Данные, характеризующие влняние галоидалкилов на активность катализатора приведены в табл. 1.

Активность катализатора оценивалась по кинетическим кривым и по выходу поли. мера в граммах на моль катализатора (за 1,5 часа).

\section{Полученные результаты и нх обсуждение}

Как показано рядом авторов $[2,11,12]$, активность катализатора, получающегося прн взаимодействии алюминийалкила с бис-циклопентадиенил-титан-дихлоридом обусловлена наличнем б-связи $\mathrm{C}$ - $\mathrm{Ti}$, по которой идет рост полимерной цепи. Так как переход к конечному неактивному комплексу связан с исчезновением этой связи и восстановлением Ті до трехвалентного состояния, то очевидно, что при использовании $\mathrm{R}_{3} \mathrm{Al}$ (сильного алкилирующего и восстанавливающего агента) цепь промежуточных реакций должна быстро доходить до конца. Иными словами, с участием $\mathrm{R}_{3} \mathrm{Al}$ скорость распада образовавшихся активных центров превышает скорость их формирования. Поскольку алкилирующая и восстановительная способность алюминийалкилов снижается в ряду $\mathrm{R}_{3} \mathrm{Al}>\mathrm{R}_{2} \mathrm{AlCl}>\mathrm{RAlCl}_{2}$, то более высокая активность систем с $\mathrm{R}_{2} \mathrm{AlCl}$ объясняется, в первую очередь, замедлением внутрикомплексных перегруппировок н, следовательно, замедлением распада активных центров. В случае же алкилалюминийдихлорида замедляется не распад активных центров, а само их формирование, и катализатор оказывается малоактивным. Если подобная оценка причин неодинаковой активности комплексов с разными алюминийалкилами правильна, то с понижением температуры, поскольку скорость реакций алкилирования уменьшается, а стабильность связи С- $\mathrm{Ti}$ увеличивается каталитическая активность $\mathrm{R}_{3} \mathrm{Al}-\left(\mathrm{C}_{5} \mathrm{H}_{5}\right)_{2} \mathrm{TiCl}_{2}$ должна возрастать. Действительно, полученные нами данные показывают, что с понижением температуры скорость образования неактивного конечного комплекса из (изо- $\left.\mathrm{C}_{4} \mathrm{H}_{9}\right)_{3} \mathrm{Al}$ и $\left(\mathrm{C}_{5} \mathrm{H}_{5}\right)_{2} \mathrm{TiCl}_{2}$ падает (табл, 2). Эти данные Таблица 2

\section{Зависимость времени образования конечного зеленого комплекса от температуры}

$\left(\mathrm{C}_{5} \mathrm{H}_{5}\right) \mathrm{TiCl}_{2}$ : (изо- $\left.\mathrm{C}_{4} \mathrm{H}_{9}\right)_{3} \mathrm{Al}=1: 4$

Растворитель - толуол

\begin{tabular}{c|c} 
Tемпература, ${ }^{\circ} \mathrm{C}$ & Время \\
\hline$+80^{\circ}$ & 20 сек \\
$+40^{\circ}$ & $1 \mathrm{мuн}$ \\
$+20^{\circ}$ & $2 \mathrm{мuн}$ \\
$+8^{\circ}$ & $5-6 \mathrm{мuн}$ \\
$-20^{\circ}$ & 1,5 час \\
$-50^{\circ}$ & $\sim 5$ час \\
$-70^{\circ}$ & не образуется \\
& В течение 6 час
\end{tabular}
позволяют грубо оценить энергию активации реакции образования конечного комплекса: она близка к 4,3 ккал/моль (рис. 1), что подтверждает ионный механизм этой реакции. В то же время активность катализа-

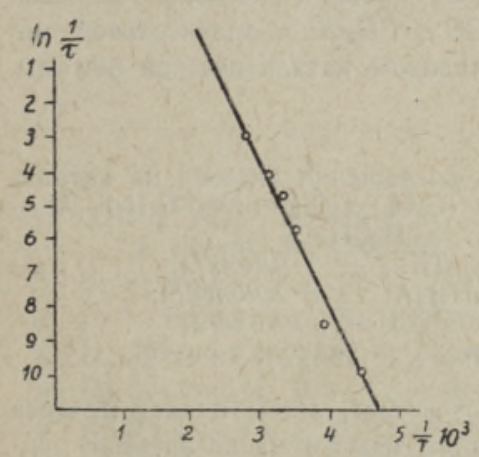
тора с понижением температуры возрастает н сохраняется в течение длительного времени (рис. 2). Катализатор сформированный при $-50^{3}$ (хотя полимеризация на нем протекала с небольшой скоростью) не терял активности даже через 14 часов.

Поскольку известно, что взаимодействие $\mathrm{R}^{\prime} \mathrm{Cl}$ с $\mathrm{R}_{3} \mathrm{Al}$ приводит к образованию $\mathrm{R}_{2} \mathrm{AlCl}$,

Рис. 1. Зависимость $\ln \frac{1}{\tau}$ от $\frac{1}{T} \cdot 10^{3}$ для реакцни образования конечного зеленого комплекса́ из $\left(\mathrm{C}_{5} \mathrm{H}_{5}\right)_{2} \mathrm{TiCl}_{2}+\left(\text { изо- } \mathrm{C}_{4} \mathrm{H}_{9}\right)_{3} \mathrm{Al}$ в толуоле.

то можно предполагать, что при введении в полимеризационную смесь определенных количеств соединений $\mathrm{c}$ подвижным атомом $\mathrm{Cl}$, малоактивная каталитическая 


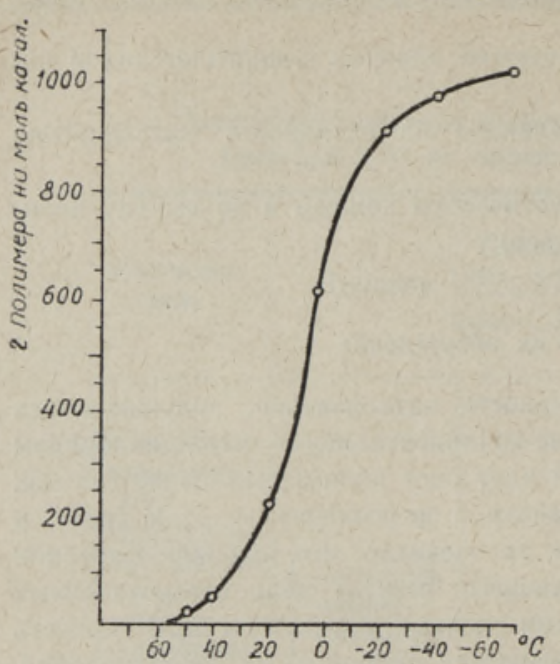

Рнс. 2. Зависимость выхода полимеpa от температуры. $\left(\mathrm{C}_{5} \mathrm{H}_{5}\right)_{2} \mathrm{TiCl}-$ 2 ммоля/л; (изо- $\left.\mathrm{C}_{4} \mathrm{H}_{9}\right)_{3} \mathrm{Al}$ 8 ммолей/л; растворитель - толуол; время 7 часов.

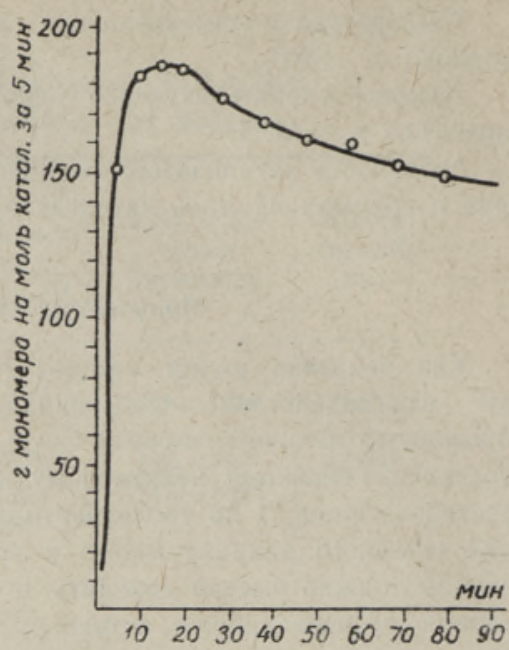

Рнс. 3. Скорость полимеризации этилена при атмосферном давлении на катализаторе

$\left(\mathrm{C}_{5} \mathrm{H}_{5}\right)_{2} \mathrm{TiCl}_{2}+$ (изо- $\left.\mathrm{C}_{4} \mathrm{H}_{9}\right)_{3} \mathrm{Al}$

$\left(\mathrm{C}_{5} \mathrm{H}_{5}\right)_{2} \mathrm{TiCl}_{2}-2$ ммоля/ת;

(изо- $\left.\mathrm{C}_{4} \mathrm{H}_{9}\right)_{3} \mathrm{Al}-8$ ммолей/ $/$

растворитель - дихлорэтан; т-ра $40^{\circ}$.

система превратится в более активную; диалкнлалюминийхлорид, полученный in situ, может быть более активным, чем введенный извне. Это предположение не только подтвердилось, но более того, повышение активности катализатора наблюдалось даже тогда, когда в системе присутствсвали такие галоидные соединения, как дихлорэтан, который с триизобутилалюминием заметно не взаимодействует. При проведении полимеризации в среде дихлорэтана скорость поглощения этилена быстро возрастает и

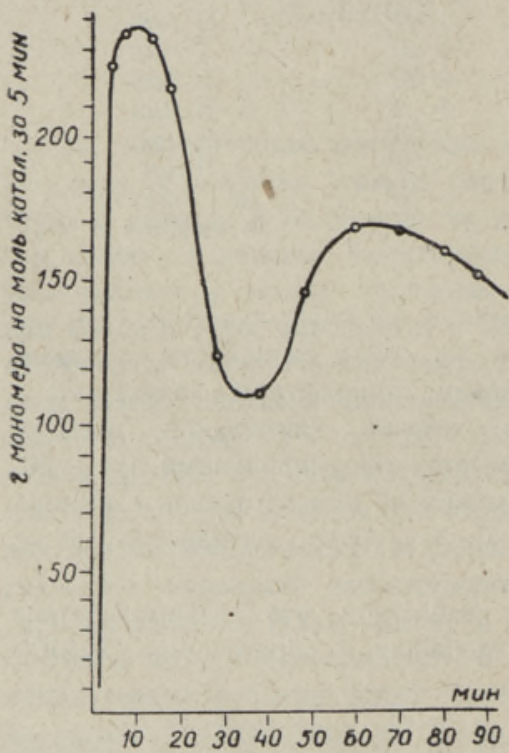
остается примерно постоянной в течение двухтрех часов (рис. 3). При применении в качестве растворителей алкилгалогенидов, содержащих в цепи более четырех атомов С или имеющих изостроение, вследствие быстрого взаимодействия растворителя с алюминийалкилом, каталитический комплекс не образуется (табл. 1). Использование этих же соединений в качестве добавок при проведении полимеризации в среде толуола дает едва заметный эффект.

Добавки $\mathrm{HCl}, \mathrm{C}_{6} \mathrm{H}_{5} \mathrm{CH}_{2} \mathrm{Cl}$ и в несколько меньшей степени $\mathrm{CH}_{2}=\mathrm{CH}-\mathrm{CH}_{2} \mathrm{Cl}$ в значительной мере повышают активность каталитической системы.

Рнс. 4. Скорость поглощения этилена на каталитической системе $\left(\mathrm{C}_{5} \mathrm{H}_{5}\right)_{2} \mathrm{TiCl}_{2}-$ (изо- $\left.\mathrm{C}_{4} \mathrm{H}_{9}\right)_{3} \mathrm{Al}-$ $\mathrm{C}_{6} \mathrm{H}_{5} \mathrm{CH}_{2} \mathrm{Cl}$.

$\left(\mathrm{C}_{5} \mathrm{H}_{5}\right)_{2} \mathrm{TiCl}_{2}-2$ мноля/ (изо- $\left.\mathrm{C}_{4} \mathrm{H}_{9}\right)_{3} \mathrm{Al}-8$ ммолей/ $\Omega$; $\mathrm{C}_{6} \mathrm{H}_{5} \mathrm{CH}_{2} \mathrm{Cl}-4$ мноля/ растворитель - толуол; т-ра $40^{\circ}$.

Скорость поглощения этилена вначале быстро возрастает, затем падает и через 20-40 мин вновь возрастает (рис. 4). Положение второго максимума по времени примерно соответствует тому моменту, когда, как мы наблюдали, в системе этнлентолуол- $\mathrm{R}_{3} \mathrm{Al}-\mathrm{R}^{\prime} \mathrm{Cl}$ при таких же температурах н концентрациях реагентов начннается 
Рнс. 5. Зависимость выхода полимера при полимернзации этилена на катализаторе $\left(\mathrm{C}_{5} \mathrm{H}_{5}\right)_{2} \mathrm{TiCl}_{2}-$

(изо- $\left.{ }_{4} \mathrm{H}_{9}\right)_{3} \mathrm{Al}$ от количества добавки $-\mathrm{C}_{6} \mathrm{H}_{5} \mathrm{CH}_{2} \mathrm{Cl}$, - - $\mathrm{HCl}$.

$\left(\mathrm{C}_{5} \mathrm{H}_{5}\right)_{2} \mathrm{TiCl}_{2}-2$ ммоля/л;

(изо- $\left.\mathrm{C}_{4} \mathrm{H}_{9}\right)_{3} \mathrm{Al}-8$ мнолей/ $/$;

растворитель - толуол; т-ра $40^{\circ}$.

реакция Фриделя-Крафтса, сопровождающаяся выделением $\mathrm{HCl}$. По-видимому, первый максимум связан с активированием катализатора полимеризации, а второй - с дополнительным расходом этнлена на алкилирование толуола.

Действие добавок хлорсодержащих соедине-

ний в значительной мере зависит от соотношения $\mathrm{Ti}: \mathrm{Al}$ : добавка (рис. 5), а также от последовательности смешения компонентов. Если добавку ввести раньше, чем (изо$\left.\mathrm{C}_{4} \mathrm{H}_{9}\right)_{3} \mathrm{Al}$, то она препятствует образованию активного комплекса. Наибольший эффект дает введение добавки сразу же после смешения остальных компонентов катализатора. Оптимальное отношение добавка: $\mathrm{R}_{3} \mathrm{Al}$ составляло $2: 1$. Увеличение этого отношения выше $5: 1$ увеличивает скорость обрыва полимерных цепей (получаются продукты с низким молекулярным весом), к преобладанию реакций алкилирования толуола этиленом и, наконец, к полному разложению катализа тора полимеризации,

\section{Выводы}

1. Причиной того, что $\mathrm{R}_{3} \mathrm{Al}$ образует с $\left(\mathrm{C}_{5} \mathrm{H}_{5}\right)_{2} \mathrm{TiCl}_{2}$ менее активный катализатор, чем $\mathrm{R}_{2} \mathrm{AlCl}$, является в первую очередь чрезмерно высокая алкилирующая и восстановительная способность $\mathrm{R}_{3} \mathrm{Al}$, приводящая к быстрому образованию неактивного конечного комплекса.

При понижении температуры превращения промежуточных комплексов замедляются, вследствие чего каталитическая активность системы возрастает.

2. Энергия активации реакции образования из (изо- $\left.\mathrm{C}_{4} \mathrm{H}_{9}\right)_{3} \mathrm{Al}$ и $\left(\mathrm{C}_{5} \mathrm{H}_{5}\right)_{2} \mathrm{TiCl}_{2}$ конечного комплекса равна $4,3 \kappa \kappa a л / м о л ь$, что свидетельствует о ионном характере процecca.

3. Если получать $\mathrm{R}_{2} \mathrm{AlCl}$ in situ (из $\mathrm{R}_{3} \mathrm{Al}$ и алкилгалогенидов) в процессе формирования каталитического комплекса, то образуется более активный катализатор полимеризации этилена, чем тогда, когда используется готовый $\mathrm{R}_{2} \mathrm{AlCl}$.

\section{Л ИТЕРАТУ РА}

1. G. Natta, P. Pino, G. Mazzanti, U. Gi annini, E. Mantica, M. Peraldo, J. Polym. Sci., 26, 120, 1957.

2. D. S. Breslow, N. R. N e w burg, J. Am. Chem. Soc., 81, 81, 1959.

3. D. S. Breslow, N. R. New burg, Chem. Eng. News, 36, 21/VII, 1958.

4. D. S. Breslow, N. R. New burg, J. Am. Chem. Soc., 79, 5072, 1957.

5. Hj. S inn, H. W inter, W. v. T ir p itz, Makromol. Chem., Bd. 48, 59, 1961.

6. A. Drucker, J. H. D a n i e 1, J. Polym. Sci., 37, 132, 553, 1959.

7. G. Natta, P. Corradini, I. N. B a s s i, J. Am. Chem. Soc., 80, 755, 1958.

8. G. Natta, P. Pino, G. Mazzanti, U. Giannini, J. Am. Chem. Soc., 79, 2975 (1957). Angew. Chem. 69, 686, 1957. 
9. А. В. Т о п иев, Г. С. Швиндлерман, Т. Г. Голенко, авт. свид. № 152877 25. V. 1962.

10. M. Houda, J. Kör b l, V. B a z a n t, R. Priby l, Chem. Listy, 51, 2259, 1957

11. F. P a t a t, H. S in n, Angew. Chem., 70, 496, 1958.

12. А. К. З е фирова, А. Е. Шилов, ДАН СССР, 136, № 3, 599, 1961.

\author{
Институт химии \\ Академии наук Эстонской ССР \\ Поступила в редакцию \\ 20. VI 1963
}

\title{
SUSTEEMI $\mathrm{R}_{3} \mathrm{AI}-\left(\mathrm{C}_{5} \mathrm{H}_{5}\right)_{2} \quad \mathrm{TiCl}_{2}$ KATALUUTILISEST AKTIIVSUSEST ETULEENI POLOMERISATSIOONIL
}

\author{
H. Kaar \\ o. Kirret,
}

Eesti NSV Teaduste Akadeemia korrespondeeriv liige

G. Schwindlerman

Resümee

Uurimuses näidatakse, et $\mathrm{R}_{3} \mathrm{Al}$ moodustab $\left(\mathrm{C}_{5} \mathrm{H}_{5}\right)_{2} \quad \mathrm{TiCl}_{2}$-ga vähema aktiivsusega katalüsti kui $\mathrm{R}_{2} \mathrm{AlCl}$. See aktiivsuse vähenemine on eeskätt tingitud $\mathrm{R}_{3} \mathrm{Al}$ suuremast alküleerivast ja redutseerivast võimest, mis pōhjustab mitteaktiivse lõppkompleksi tekke.

Temperatuuri alandamisel aeglustub vaheproduktkomplekside muundumine, mille tagajärjel tôuseb süsteemi katalüütiline aktiivsus.

$\mathrm{Al}$ (iso- $\left.\mathrm{C}_{4} \mathrm{H}_{9}\right)_{3}$ ja $\left(\mathrm{C}_{5} \mathrm{H}_{5}\right)_{2} \quad \mathrm{TiCl}_{2}$ lopppkompleksi tekkereaktsiooni aktiveerimise energia vōrdub $4,3 \mathrm{kcal} / \mathrm{mooliga}$, mis tõestab protsessi ioonset iseloomu.

Kui saada $\mathrm{R}_{2} \mathrm{AlCl}$ katalüütilise kompleksi moodustumise protsessis in situ, s. o. R $\mathrm{R}_{3} \mathrm{Al}$ ja alküülhalogeniididest, siis tekib etüleeni polümerisatsiooniks suurema aktiivsusega katalüst kui valmis $\mathrm{R}_{2} \mathrm{AlCl}$ kasutades.
Eesti NSV Teaduste Akadeemia
Keemia Instituut
Saabus toimetusse
20. VI 1963

\section{ON CATALYTIC ACTIVITY OF THE SYSTEM $\mathrm{R}_{3} \mathrm{Al}-\left(\mathrm{C}_{5} \mathrm{H}_{5}\right)_{2} \mathrm{TiCl}_{2}$ IN POLYMERIZATION OF ETHYLENE}

\author{
H. Kaar \\ O. Kirret, \\ Corresponding member of the Academy of Sciences of the Estonian S.S.R.
}

G. Schwindlerman

Summary

In the article it is shown that $\mathrm{R}_{3} \mathrm{Al}-\left(\mathrm{C}_{5} \mathrm{H}_{5}\right)_{2} \mathrm{TiCl}_{2}$ forms a catalyst with a weaker activity than $\mathrm{R}_{2} \mathrm{AlCl}$, and that particularly owing to the alkylating and reducing effect of $R_{3} A l$ which calls forth a formation of the non-active final complex.

At a lowering of the temperature the mutation of intermediate product complexes slows down, and, as a result, the catalytic activity of the system increases.

The activizing energy of the formation reaction of the final complex of $\mathrm{Al}$ (iso- $\left.\mathrm{C}_{4} \mathrm{H}_{9}\right)_{3}$ and $\left(\mathrm{C}_{5} \mathrm{H}_{5}\right)_{2} \mathrm{TiCl}_{2}$ is $4.3 \mathrm{kcal} / \mathrm{mol}$, which is proof of the ionic character of the process.

Obtaining $\mathrm{R}_{2} \mathrm{AlCl}$ in situ (from $\mathrm{R}_{3} \mathrm{Al}$ and alkylhalogenites) in the process of catalytic complex formation, we get a catalytic system with a higher activity for the polymerization of ethylene than with $\mathrm{R}_{2} \mathrm{AlCl}$.

Academy of Sciences of the Estonian S.S.R.,

Received Institute of Chemistry 